\title{
Effect of site of transfer on pregnancy and twinning rates following bilateral egg transfer in the cow
}

\author{
J. M. Sreenan and D. Beehan \\ The Agricultural Institute, Belclare, Galway, Ireland
}

High pregnancy and egg survival rates can be achieved following surgical egg transfer techniques in the cow (Rowson, Lawson \& Moor, 1971; Sreenan, Beehan \& Mulvehill, 1975). The application of such techniques under farm conditions requires the development of simple non-surgical transfer techniques, but attempts to develop such procedures have so far resulted in pregnancy and egg survival rates much lower than those achieved by surgical techniques (Rowson \& Moor, 1966; Sreenan, 1975; Lawson, Rowson, Moor \& Tervit, 1975; Boland, Crosby \& Gordon, 1975), perhaps because of egg expulsion or the introduction of uterine infection (Rowson, Lamming \& Fry, 1953; Rowson, Bennett \& Harper, 1964). More recent work indicates a trend towards improved pregnancy rates when non-surgical transfers are carried out between Days 6 to 9 of the oestrous cycle rather than earlier (Lawson et al., 1975; Sreenan, 1975).

The present work was carried out to determine whether site of transfer by surgical methods had any effect on pregnancy and egg survival rates.

Superovulation was induced in donor animals (Hereford-cross heifers) weighing $300-360 \mathrm{~kg}$ by i.m. injections of 2000 i.u. PMSG (Intervet), followed by $500 \mu$ g cloprostenol (I.C.I. 80,996 , a prostagiandin analogue) 48 and $72 \mathrm{hr}$ later. The donor heifers were artificially inseminated at the induced oestrus with frozen semen. Recipients were Hereford-cross heifers weighing $275-350 \mathrm{~kg}$. Oestrous cycles in the recipients were exactly synchronized with those of the donor animals by i.m. injection of $500 \mu \mathrm{g}$ cloprostenol during the luteal phase of the cycle. In one group of randomly chosen recipients, one fertilized egg was transferred to the tip of each uterine horn approximately $40 \mathrm{~mm}$ from the uterotubal junction. In the second group, one fertilized egg was transferred to the lower part of each uterine horn near the common body of the uterus. The point of entry of the transfer pipette in this group was at the external attachment of the uterine horns. All eggs were transferred in $0.20 \mathrm{ml}$ medium (TCM 199) and were expelled towards the ovarian end. Fertilized eggs from the same donor were transferred within $120 \mathrm{~min}$ of recovery to all the animals in each group. Egg recovery and transfer was carried out surgically under closed circuit anaesthesia as previously described (Sreenan et al., 1975). Pregnancy rate and site of egg survival was established following slaughter of all the recipients at 30 days from the day of oestrus before the transfer. Egg survival rates were based on recovery of viable embryos at slaughter.

The results of the transfers are given in Table 1. There was no difference in pregnancy or egg survival rates relative to site of transfer within the uterus when transfers were carried out from Days 6-8 of the cycle. The position of the fertilized eggs relative to the CL did not seem to affect survival. The overall pregnancy rate of $75 \%$ and twinning rate of $66.6 \%$ are in agreement with previous reports (Rowson et al., 1971; Sreenan et al., 1975).

The data presented here show that the surgical transfer of 6-8-day-old fertilized eggs to a position near the common body of the uterus did not reduce their survival rate. While this finding cannot be directly extrapolated to non-surgical transfer methods, it does indicate that site of transfer would be worth testing in such experiments.

We thank Mr M. J. Cooper, I.C.I. Ltd, for the prostaglandin analogue (I.C.I. 80,996), Mr. A. McDonagh and Mr G. Morris for technical assistance, and Mr P. Creaven and F. Costelloe for help at all stages of the work, which was supported by the commission of the European Communities. 
Table 1. Effect of site of transfer on egg survival in heifers after bilateral egg transfers

\begin{tabular}{|c|c|c|c|c|c|c|c|}
\hline \multirow{2}{*}{$\begin{array}{c}\text { Animal } \\
\text { No. }\end{array}$} & \multirow{2}{*}{$\begin{array}{c}\text { Day of egg } \\
\text { transfer }\end{array}$} & \multicolumn{2}{|c|}{$\begin{array}{c}\text { Transfer } \\
\text { near uterotubal } \\
\text { junction }\end{array}$} & \multirow{2}{*}{$\begin{array}{c}\text { Animal } \\
\text { No. }\end{array}$} & \multirow{2}{*}{$\begin{array}{c}\text { Day of egg } \\
\text { transfer }\end{array}$} & \multicolumn{2}{|c|}{$\begin{array}{c}\text { Transfer near } \\
\text { common uterine } \\
\text { body }\end{array}$} \\
\hline & & $+\mathrm{CL}$ & $-\mathrm{CL}$ & & & $+\mathrm{CL}$ & $-\mathrm{CL}$ \\
\hline 736 & 5 & - & - & 735 & 4 & - & - \\
\hline 721 & 6 & + & d & 643 & 5 & + & - \\
\hline 709 & 7 & - & - & 727 & 6 & + & + \\
\hline 710 & 7 & - & + & 713 & 7 & + & + \\
\hline 717 & 7 & + & + & 691 & 7 & + & + \\
\hline 673 & 7 & + & + & 705 & 7 & - & - \\
\hline 692 & 7 & d & + & 694 & 8 & + & + \\
\hline 700 & 7 & + & + & 509 & 8 & + & d \\
\hline 712 & 8 & + & + & 724 & 8 & + & + \\
\hline 649 & 8 & + & + & 707 & 8 & d & d \\
\hline
\end{tabular}

\section{References}

Boland, M.P., Crosby, T.F. \& Gordon, I. (1975) Twin pregnancy in cattle established by non-surgical transfer. Br. vet. J. 131, 738-740.

LAwSON, R.A.S., Rowson, L.E.A., Moor, R.M. \& TERVIT, H.R. (1975) Experiments on egg transfer in the cow and ewe: dependence of conception rate on the transfer procedure and stage of the oestrous cycle. J. Reprod. Fert. 45, 101-107.

Rowson, L.E.A. \& MooR, R.M. (1966) Non-surgical transfer of cow eggs. J. Reprod. Fert. 11, 311-312.

Rowson, L.E.A., LAmming, G.E. \& FRY, R.M. (1953) The relationship between ovarian hormones and uterine infection. Vet. Rec. 65, 335.
Rowson, L.E.A., BenNetT, J.P. \& HARPER, M.J.K. (1964) The problem of non-surgical egg transfer to the cow uterus. Vet. Rec. 76, 21-23.

Rowson, L.E.A., LAwson, R.A.S. \& Moor, R.M. (1971) Production of twins in cattle by egg transfer. J. Reprod. Fert. 25, 261-268.

SreENAN, J.M. (1975) Successful non-surgical transfer of fertilised cow eggs. Vet. Rec. 96, 490-491.

Sreenan, J.M., BeehaN, D. \& Mulvehill, P. (1975) Egg transfer in the cow: factors affecting pregnancy and twinning rates following bilateral transfers. $J$. Reprod. Fert. 44, 77-85. 